\section{A Two-step Pretreatment Significantly Enhances Shoot Organogenesis from Leaf Explants of Highbush Blueberry cv. Bluecrop}

\author{
Xiaoling $\mathrm{Cao}^{1}$ and Freddi A. Hammerschlag ${ }^{2}$ \\ Fruit Laboratory, Agricultural Research Service, U.S. Department of \\ Agriculture, 10300 Baltimore Avenue, Beltsville, MD 20705
}

Larry Douglass ${ }^{3}$

Animal and Avian Sciences Department, Animal Science/Agriculture Engineering Building, University of Maryland, College Park, MD 20742-2311

Additional index words. Ericaceae, shoot regeneration, thidiazuron, tissue culture, Vaccinium corymbosum

\begin{abstract}
As part of a program to improve highbush blueberry (Vaccinium corymbosum L.) cultivars via tissue culture and genetic engineering, studies were conducted to determine optimum conditions for organogenesis from leaf explants of the previously recalcitrant $\mathrm{cv}$. Bluecrop. The effects of a pretreatment, growth regulators, and age of explant source on shoot organogenesis were investigated. A maximum of $98 \%$ explants regenerated shoots with a mean of 11 shoots per leaf explant after 62 days when explants of 2-week-old shoot cultures were incubated on the following regime: pretreatment medium \#1 containing $5 \mu \mathrm{M}$ TDZ and 2.6 $\mu_{\mathrm{M}}$ NAA for 4 days, pretreatment medium \#2 containing $7 \mu_{\mathrm{m}}$ zeatin riboside and 2.6 $\mu_{\mathrm{M}}$ NAA for 3 days, regeneration medium containing $1 \mu_{\mathrm{M}}$ TDZ for 6 weeks, and last on medium without growth regulators for 10 days. No shoot regeneration occurred if explants were incubated without exposure to pretreatment prior to incubation on regeneration medium. There were no significant differences in percentage of regeneration or the number of shoots regenerating per explant from leaf explants derived from either 1-, 2-, or 3-week-old shoot cultures. Shoot production per explant on regeneration medium containing $1 \mu_{\mathrm{M}} \mathrm{TDZ}$ was about three times that on $0.5 \mu_{\mathrm{M}} \mathrm{TDZ}$ or $20 \mu_{\mathrm{M}}$ zeatin riboside, and nine times that on $5 \mu \mathrm{M}$ TDZ. Chemical names used: 1-phenyl-3-(1,2,3-thiadiazol-5yl)urea (thidiazuron, TDZ); 9-( $\beta$-D-ribofuranosyl)-6-(4-hydroxy-3-methyl-but-2enylamino)purine (zeatin riboside).
\end{abstract}

Heterozygosity and polyploidy impede improvement of highbush blueberry by traditional breeding methods; thus, this species is a good candidate for improvement via tissue culture and genetic engineering. Increasing leaf regeneration efficiency is critical for the development of a transformation system using either Agrobacterium tumefaciens as a vector and/or the biolistic process. Only a few reports exist of shoot organogenesis from leaf explants of commercially important cultivars of highbush blueberry (Billings et al., 1988; Callow et al., 1989; Rowland and Ogden, 1992), and these studies focused on plant growth regulator and genotype effects. Callow et al.

Received for publication 20 Sept. 2001. Accepted for publication 17 Mar. 2002. Use of a company or product name does not imply approval or recommendation of the product to the exclusion of others, which may also be suitable.

${ }^{1}$ Visiting Research Horticulturist; Shaanxi Fruit Crops Research Center, 20 Dong-Yi Road, Xian, Shaanxi, 710061, Peoples Republic of China. Current address: 11248 Evans Trail \#3, Beltsville, MD 20705.

${ }^{2}$ Supervisory Plant Physiologist/Research Leader; e-mail address: hammersf@ba.ars.usda.gov; to whom reprint requests should be addressed.

${ }^{3}$ Professor and Associate Chair.
(1989) achieved regeneration frequencies of only one shoot per explant for 'Bluecrop', the most widely grown blueberry cultivar in North America (Moore, 1994; Ehlenfeldt, personal communication). Rowland and Ogden (1992) demonstrated that the cytokinin conjugate zeatin riboside (ZR) at $20 \mu \mathrm{M}$ was more effective for blueberry shoot regeneration than either zeatin or $6(\gamma, \gamma$ - dimethylallylamino)-purine (2iP). They induced a maximum regeneration of 20 shoots per leaf explant for 'Sunrise', but were unable to induce shoot regeneration from either 'Bluecrop' or 'Duke'. Studies with other woody species have demonstrated that factors such as age of explant source, age of explant, the cytokinin-like compound TDZ and length of dark period and photosynthetic photon flux $(P P F)$ have significant effects on adventitious shoot formation (Hammerschlag and Litz, 1992; Huetteman and Preece, 1993; Murthy et al., 1998). Thus, in a previous study, we investigated the effects of these factors on regeneration of shoots from leaf explants of several commercially important highbush blueberry cultivars. Although we demonstrated maximum shoot regeneration of $\approx 13$ shoots per explant for cvs. Duke, Georgiagem, Sierra, and five for Jersey on regeneration medium with $20 \mu \mathrm{m}$ zeatin ribo- side and under a $P P F$ of $55 \pm 5 \mu \mathrm{mol} \cdot \mathrm{m}^{-2} \cdot \mathrm{s}^{-1}$, 'Bluecrop' did not regenerate shoots under any of the conditions investigated (Cao and Hammerschlag, 2000). In gene delivery studies with 'Bluecrop' and other blueberry cultivars (Cao et al., 1998), we found explant pretreatments to be important for the early stages of transformation. The aim of the present work was to investigate the effects of a twostep pretreatment, growth regulators in the shoot regeneration medium, and age of explant source on shoot organogenesis from leaf explants of the commercially important, previously recalcitrant 'Bluecrop'.

\section{Materials and Methods}

Plant material and propagation medium. Leaf-blade explants were dissected from 1- to 3 -week-old, in vitro-cultured shoots of northern highbush blueberry cv. Bluecrop. Donor shoot cultures were maintained by transferring 1- to 2-cm-long axillary shoots at 4-week intervals onto $42.5 \mathrm{~mL}$ of a blueberry basal medium (Rowland and Ogden, 1992) consisting of woody plant medium (Lloyd and McCown, 1980) modified as follows $\left(\mathrm{mg} \cdot \mathrm{L}^{-1}\right)$ : $684 \mathrm{Ca}\left(\mathrm{NO}_{3}\right)_{2} \cdot 4 \quad \mathrm{H}_{2} \mathrm{O}, 190 \mathrm{KNO}_{3}, 73.4$ $\mathrm{C}_{10} \mathrm{H}_{13} \mathrm{FeN}_{2} \mathrm{NaO}_{8}$ [EDTA; (ethylenedinitriol)tetraacetic acid ferric-sodium salt], and 0.1 thiamine $\cdot \mathrm{HCl}$, and without $\mathrm{K}_{2} \mathrm{SO}_{4}, \mathrm{CaCl}_{2}$, $\mathrm{FeSO}_{4}$, and $\mathrm{Na}_{2}$ EDTA. The medium also contained $15 \mathrm{~mm}$ sucrose, Difco Bacto-agar (5.5 $\left.\mathrm{g} \cdot \mathrm{L}^{-1}\right), 24.6 \mu \mathrm{m} 2 \mathrm{iP}$, and $9.1 \mu \mathrm{m}$ zeatin. The $\mathrm{pH}$ was adjusted to 5.2 before autoclaving at 121 ${ }^{\circ} \mathrm{C}$ at $131 \mathrm{kPa}$ for $15 \mathrm{~min}$; the medium was then dispensed into glass jars that were sealed with plastic wrap. Shoot cultures were incubated at $23{ }^{\circ} \mathrm{C}$ with a 16 -h photoperiod provided by cool-white fluorescent lights at a $P P F$ of 40 $\mu \mathrm{mol} \cdot \mathrm{m}^{-2} \cdot \mathrm{s}^{-1}$.

Shoot organogenesis. Leaf explants from 1-, 2-, and 3-week-old shoot cultures were prepared by dissecting perpendicular to the midrib of two to three of the youngest, fullyexpanded leaves to remove the petiole and the distal third portion of the blade. The remaining proximal portion of the leaf blade was placed abaxial side up on sterile filter paper in $100 \times$ $15-\mathrm{mm}$ petri dishes saturated with $\mathrm{pH} 5.4$ liquid pretreatment medium \#1 (PT1) containing N6 macro salts (Chu et al., 1975), LS micro salts (Linsmaier and Skoog, 1965), $0.56 \mu \mathrm{M}$ myo-inositol, $3 \mu \mathrm{M}$ thiamine $\mathrm{HCl}, 5 \mu \mathrm{M}$ TDZ, $1.1 \mu \mathrm{m}$ naphthaleneacetic acid (NAA), $87.6 \mathrm{~mm}$ sucrose and casein hydrolysate $\left(300 \mathrm{mg} \cdot \mathrm{L}^{-1}\right)$, and incubated in the dark at $23{ }^{\circ} \mathrm{C}$ for $4 \mathrm{~d}$. Explants were blotted, transferred to filter paper saturated with $\mathrm{pH} 5.4$ liquid pretreatment medium \#2 (PT2) containing blueberry basal medium (as above) supplemented with $20 \mu \mathrm{M}$ zeatin riboside and $2.5 \mu \mathrm{M}$ NAA, and incubated in the dark at $23^{\circ} \mathrm{C}$ for $3 \mathrm{~d}$. PT 1 and PT2 were based on previous transformation experiments with apples (Hammerschlag et al., 1997; Liu et al., 2001) and gene delivery studies with blueberries (Cao et al., 1998). Explants with and without (from shoots maintained on propagation medium) the two-step pretreatment were transferred to regeneration medium consisting of blueberry basal medium 
supplemented with either $0.5,1.0$, or $5.0 \mu \mathrm{M}$ TDZ or $20 \mu \mathrm{M} Z R$. Explants were incubated in dark for 1 week, and then incubated at $23{ }^{\circ} \mathrm{C}$, under a 16 -h photoperiod provided by coolwhite fluorescent lights at a $P P F$ of $55 \pm 5$ $\mu \mathrm{mol} \cdot \mathrm{m}^{-2} \cdot \mathrm{s}^{-1}$. Explants were transferred to fresh medium every 2 weeks. After 6 weeks, explants were transferred to the same medium without growth regulators for $10 \mathrm{~d}$ and then scored for percentage of regenerating explants and for mean number of shoots per explant.

Data collection and statistical analyses. Petri dishes were arranged in a completely randomized design. Regeneration experiments were replicated a minimum of three times with 10 leaf explants per treatment per replication. Data for number of shoots per explant were analyzed by analysis of variance techniques using the generalized linear model procedures of SAS (version 6.12) (SAS Institute, 1997). Differences among means were tested using the LSD test, $P \leq 0.05$.

\section{Results and Discussion}

Influence of pretreatment. The two-step growth regulator pretreatment significantly enhanced the efficiency of shoot organogenesis from leaf explants of 'Bluecrop' (Figs. 1 and 2). Pretreatment vs. no pretreatment experiments found pretreatment to be a significant factor in 10 of 12 treatments (all except 1week cultures on either 0.5 or $5 \mu \mathrm{M}$ TDZ) (Fig. 1). Similar to previous results (Cao and Hammerschlag, 2000), no shoot regeneration occurred when 'Bluecrop' leaf explants were dissected and transferred directly to shoot regeneration medium. Pretreatments have also been effective for increasing shoot organogenesis in Rubus and Malus (Swartz et al., 1990) and in Prunus (Antonelli and Druart, 1989), but in these cases, shoot cultures received the pretreatment prior to explant excision. In the present study, we investigated the effect of a pretreatment on shoot regeneration because we found the same pretreatment to be important for the early stages of blueberry transformation using Agrobacterium (Cao et al., 1998), and because in Agrobacteriummediated transformation experiments, explants generally receive some type of pretreatment prior to placement on regeneration medium. Our PT1 medium was based on a pretreatment (cocultivation) medium used for apple transformations (Hammerschlag et al., 1997; Liu et al., 2001) and was also used as a pretreatment (cocultivation) medium for our studies on the early stages of blueberry transformation (Cao et al., 1998). For the blueberry transformation studies, we initially substituted ZR for TDZ in our blueberry cocultivation medium since ZR was shown to be more effective than TDZ in our blueberry regeneration studies (Cao and Hammerschlag, 2000). However, when TDZ was replaced by ZR, our GUS assays were negative (Cao and Hammerschlag, unpublished data); thus, we replaced ZR with TDZ for cocultivation and continued to use TDZ as a pretreatment in the present regeneration studies. PT2 was added as a pretreatment medium because it too is being used in our blueberry
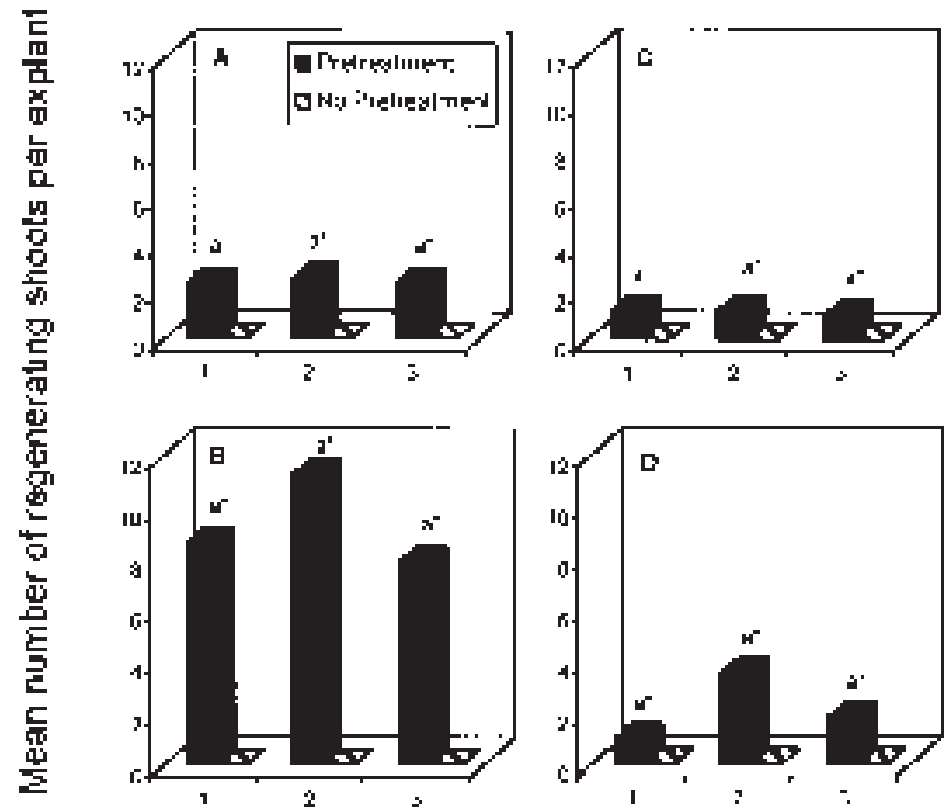

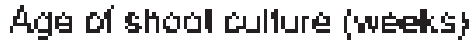

Fig. 1. Influence of age of culture on the mean number of shoots that regenerated from 'Bluecrop' leaf explants either exposed or not exposed to a two-step pretreatment prior to placement on regeneration medium with (A) $0.5 \mu \mathrm{M}$ TDZ, (B) $1 \mu \mathrm{M}$ TDZ, (C) $5 \mu \mathrm{M}$ TDZ, or (D) $20 \mu \mathrm{M}$ ZR. Mean separation within growth regulator treatment by LSD, $P \leq 0.05$. Significant effects of pretreatment $(P \leq 0.05)$ within age of culture and growth regulator treatment are indicated by asterisks.

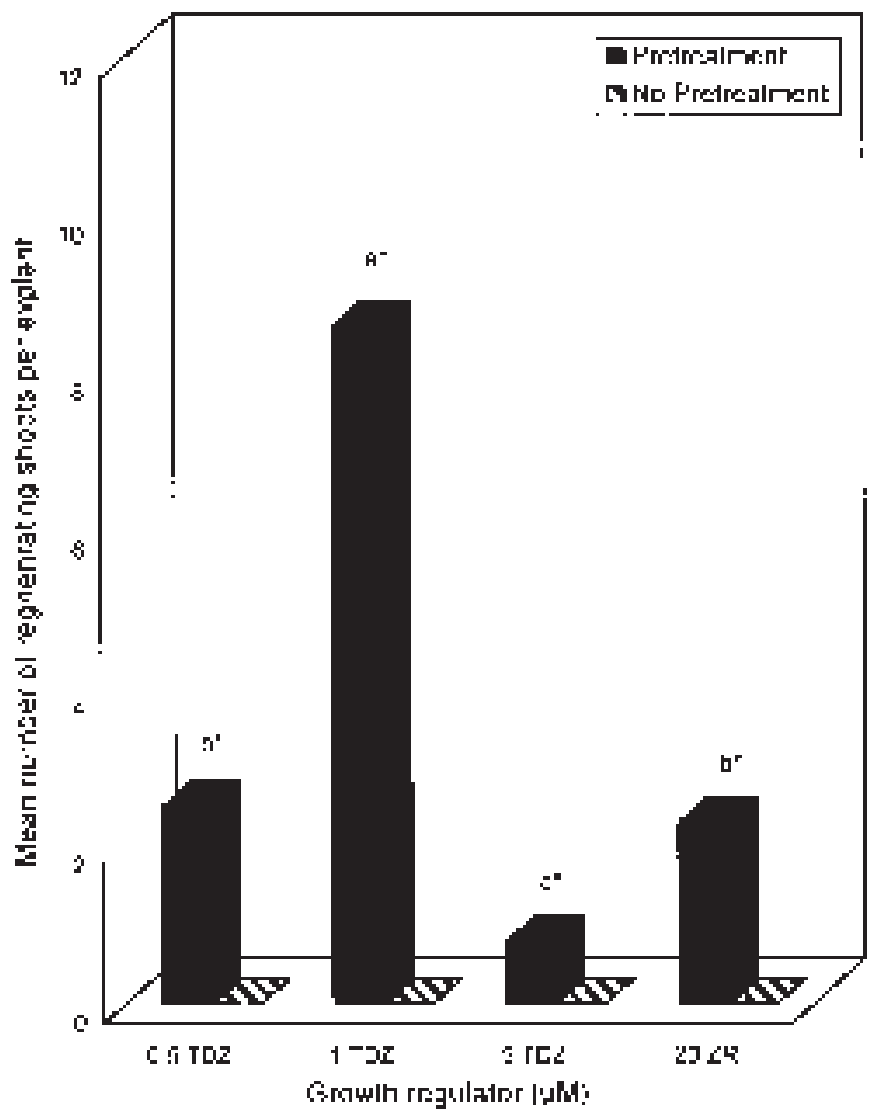

Fig. 2. Influence of thidiazuron (TDZ) and zeatin riboside (ZR) in the shoot regeneration medium on the mean number of shoots that regenerated from 'Bluecrop' leaf explants either exposed or not exposed to a two-step pretreatment. Mean separation within growth regulator treatment by LSD, $P \leq 0.05$. Significant effects of pretreatment $(P \leq 0.05)$ within growth regulator treatments are indicated by asterisks. 
transformation experiments (Cao and Hammerschlag, unpublished data). Although pretreatment of the cultures on PT1 and PT2 added one extra week of dark treatment, previous studies (Cao and Hammerschlag, 2000) have demonstrated that 1 or 2 weeks in the dark were equally effective for blueberry regeneration.

Influence of age of explant source. Age of shoot culture did not influence the number of 'Bluecrop' shoots regenerating per explant when a pretreatment was included in the regeneration experiments (Fig. 1). These results are similar to what was reported previously for regeneration from leaves of cvs. Duke, Georgiagem, Jersey, and Sierra in the absence of pretreatments (Cao and Hammerschlag, 2000). However, in contrast to these results, age of shoot culture was of significance for the early stages of transformation of cvs. Bluecrop, Duke, and Sierra, which includes an explant pretreatment (Cao et al., 1998).

Influence of $T D Z$ and $Z R$. Following the two-step pretreatment, percentage of regeneration on medium with $1 \mu \mathrm{M}$ TDZ was about double $(100 \%)$ that on medium containing either 0.5 , or $5 \mu \mathrm{M}$ TDZ or $20 \mu \mathrm{M} Z \mathrm{ZR}$ (Table 1). Also, significantly more shoots per explant were produced on this medium than on any of the other media (Fig. 2). In early highbush blueberry regeneration studies (Billings et al., 1988; Callow et al., 1989), 2iP was the preferred growth regulator and a maximum of seven shoots per regenerating leaf segment was achieved for cvs. Berkley and Bluehaven. Rowland and Ogden (1992) initiated studies to examine the effects of $\mathrm{ZR}$ on regeneration from leaf explants of highbush cvs. Sunrise, Duke and Bluecrop based on the studies with tomato (Tatchell and Binns, 1986) and potato (Sheerman and Bevan, 1988) that reported that the cytokinin conjugate ZR was superior to other cytokinins for shoot regeneration from leaf explants. ZR stimulated two and five times the number of shoots per 'Sunrise' explant than zeatin and $2 \mathrm{iP}$, respectively; however, commercially important cvs. Duke and Bluecrop were unresponsive to all regeneration media tested. In our recent studies (Cao and Hammerschlag, 2000) with cvs. Duke, Georgiagem, Jersey, and Sierra, maximum percentage of regeneration either occurred on $20 \mu \mathrm{M}$ ZR or was similar on $1 \mu \mathrm{M}$ TDZ and 20 $\mu \mathrm{M} Z \mathrm{ZR}$. Maximum number of shoots regenerating per explant for these four cultivars occurred on ZR. Only $20 \mu \mathrm{M}$ ZR was used in our
Table 1. Mean shoot regeneration frequency of pretreated leaf explants of highbush blueberry cv. Bluecrop as a function of growth regulators in the regeneration medium and age of explant source. ${ }^{2}$

\begin{tabular}{lccc}
\hline \hline Growth & \multicolumn{3}{c}{ Age of culture (weeks) } \\
\cline { 2 - 4 } regulator $(\mu \mathrm{M})$ & 1 & 2 & 3 \\
\hline $0.5 \mathrm{TDZ}$ & $50 \pm 18$ & $55 \pm 15$ & $55 \pm 13$ \\
$1.0 \mathrm{TDZ}$ & $100 \pm 0$ & $98 \pm 2.5$ & $93 \pm 5$ \\
$5.0 \mathrm{TDZ}$ & $58 \pm 18$ & $48 \pm 10$ & $40 \pm 12$ \\
$20 \mathrm{ZR}$ & $60 \pm 12$ & $60 \pm 18$ & $68 \pm 10$
\end{tabular}

${ }^{\mathrm{z}}$ Each value represents the mean \pm SE of a minimum of three replications with 10 explants per treatment per replication. $\mathrm{TDZ}=$ thidiazuron; $\mathrm{ZR}=$ zeatin riboside.

previous and present studies because earlier studies (Rowland and Ogden, 1992) demonstrated this to be the optimum concentration for shoot regeneration from leaf explants of blueberry cv. Sunrise. The present study demonstrates the importance of a pretreatment and TDZ for 'Bluecrop' shoot regeneration. Studies with other Vaccinium species have demonstrated the importance of TDZ for shoot regeneration (Shibli and Smith, 1996), and this growth regulator has been shown to induce either organogenesis or embryogenesis of many woody fruit crop genera (Heutteman and Preece, 1993; Murthy et al., 1998).

In summary, a simple, reliable protocol for high efficiency shoot regeneration from leaf explants of 'Bluecrop' is reported that relies on a two-step pretreatment and regeneration on TDZ medium. This protocol will facilitate using genetic transformation and tissue culture technologies to improve commercially important 'Bluecrop' and may be potentially useful for other recalcitrant woody species.

\section{Literature Cited}

Antonelli, M. and Ph. Druart. 1989. The use of a 2,4D pretreatment to induce leaf regeneration on

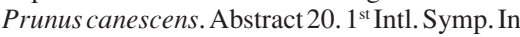
Vitro Cult. Hort. Breed., Cesena, Italy.

Billings, S.G., C.K. Chin, and G. Jelenkovic. 1988. Regeneration of blueberry plantlets from leaf segments. HortScience 23:763-776.

Callow, P., K. Haghighi, M. Giroux, and J. Hancock. 1989. In vitro shoot regeneration on leaf tissue from micropropagated highbush blueberry. HortScience 24:373-375

Cao, X., Q. Liu, L.J. Rowland, and F.A. Hammerschlag. 1998. GUS expression in blueberry (Vaccinium spp.): Factors influencing Agrobacterium-mediated gene transfer efficiency. Plant Cell Rpt. 18:266-270.
Cao, X. and F.A. Hammerschlag. 2000. Improved shoot organogenesis from leaf explants of highbush blueberry. HortScience 35:945-947.

Chu, D.D., K.K. Wang, C.S. Sun, D. Hsu, K.C. Yin, C.Y. Chu, and F.Y. Pi. 1975. Establishment of an efficient medium for anther culture of rice through comparative experiments on the nitrogen sources. Sci. Sinica 18:659-688.

Hammerschlag, F.A. and R.E. Litz. 1992. Biotechnology of perennial fruit crops. CAB Intl., Wallingford, U.K.

Hammerschlag, F.A., R.H. Zimmerman, U.L. Yadava, S. Hunsucker, and P. Gercheva. 1997. Effect of antibiotics and exposure to an acidified medium on the elimination of Agrobacterium tumefaciens from apple leaf explants and on shoot regeneration. J. Amer. Soc. Hort. Sci. 122:758-763.

Huetteman, C.A. and J.E. Preece. 1993. Thidiazuron: A potent cytokinin for woody plant tissue culture. Plant Cell Tissue Organ Cult. 33:105-119.

Linsmaier, E.M. andF. Skoog. 1965. Organic growth factor requirements of tobacco tissue cultures. Physiol. Plant. 18:100-127.

Liu, Q., J. Ingersoll, L. Owens, S. Salih, and F. Hammerschlag. 2001. Response of transgenic RoyalGalaapple(Malus $\times$ domestica Borkh.) shoots carrying a modified cecropin MB39 gene, to Erwinia amylovora. Plant Cell Rpt. 20:306-312.

Lloyd, G. and B. McCown. 1980. Commercially feasible micropropagation of mountain laurel, Kalmia latifolia, by use of shoot tip culture. Proc. Intl. Plant Prop. Soc. 30:421-427.

Moore, J.N. 1994. The blueberry industry of North America. HortTechnology 4:96-102.

Murthy, B.N., S.J. Murch, and P.D. Saxena. 1998. Thidiazuron: A potent regulator of in vitro plant morphogenesis. In Vitro Cell. Dev. Biol.-Plant 34:267-275.

Rowland, L.J. and E.L. Ogden. 1992. Use of a cytokinin conjugate for efficient shoot regeneration from leaf sections of highbush blueberry. HortScience 27:1127-1129.

SAS Institute. 1997. SAS/STAT guide for personal computers. Ver. 6.12. SAS Institute, Cary, N.C.

Sheerman, S. And M.W. Bevan. 1988. A rapid transformation method for Solanum tuberosum using binary Agrobacterium tumefaciens vectors. Plant Cell Rpt. 7:13-16.

Shibli, R.A. and M.A.L. Smith. 1996. Direct shoot regeneration from Vaccinium pahalae (ohelo) and $V$. myrtillus (bilberry) leaf explants. HortScience 31:1225-1228.

Swartz, H.J., R. Bors, F. Mohamed, and S.K. Naess. 1990. The effect of in vitro pretreatments on subsequent shoot organogenesis from excised Rubus and Malus leaves. Plant Cell Tissue Organ Cult. 21:179-184.

Tatchell, S. And A.N. Binns. 1986. A modified MS media for regeneration of direct explants and long term callus cultures of tomato. Tomato Genetics Co-op Nwsl. 36:35-36. 